Article

\title{
Phase Selection during Solidification of Ni-10.95 at. \% and B-3.23 at. \% Si Alloy
}

\author{
Karla L. Fraga-Chávez ${ }^{1}$, Manuel Jesús Castro-Román ${ }^{1, *}$, Martín Herrera-Trejo ${ }^{1}$, \\ Luciano Eliezer Ramírez-Vidaurri ${ }^{2}$ and Israel Aguilera-Luna ${ }^{3}$ \\ 1 Centro de Investigación y de Estudios Avanzados del Instituto Politécnico Nacional, Saltillo, \\ 25900 Ramos Arizpe, Coahuila, Mexico; karla.fraga@cinvestav.edu.mx (K.L.F.-C.); \\ martin.herrera@cinvestav.edu.mx (M.H.-T.) \\ 2 Instituto Tecnológico de Saltillo, 25280 Saltillo, Coahuila, Mexico; elramirez@itsaltillo.edu.mx \\ 3 Fundición de Aleaciones Especiales de Mexico S. A. de C.V., 25100 Saltillo, Coahuila, Mexico; \\ iaguileral01@gmail.com \\ * Correspondence: manuel.castro@cinvestav.edu.mx; Tel.: +52-844-438-9600 (ext. 8652)
}

Academic Editor: Anders E. W. Jarfors

Received: 13 February 2017; Accepted: 16 May 2017; Published: 24 May 2017

\begin{abstract}
To gain insight into the solidification of the Ni-10.95 at. \% and B-3.23 at. \% Si alloy, 29 cast samples extracted from a casting of this alloy were remelted under an Ar atmosphere, using either DSC or an in-house thermal analysis apparatus. $\mathrm{Ni}(\mathrm{fcc})$ and $\mathrm{Ni}_{3} \mathrm{~B}$ phases were identified by $\mathrm{X}$-ray diffraction of both the remelted and original cast samples; however, microstructural differences were observed between the two. These microstructural differences are associated with the high undercooling observed during the eutectic reaction in the remelted samples. This high undercooling results from the difficulty of $\mathrm{Ni}_{3} \mathrm{~B}$ nucleation, which allows the formation of a $\mathrm{Ni}_{x} \mathrm{~B}_{y}$ metastable phase. Metallographic inspection shows that the metastable phase solidifies at least partially through a non-cooperative growth mechanism. This metastable phase may be the elusive $\mathrm{Ni}_{23} \mathrm{~B}_{6}$ phase. The melting temperature of the metastable phase is $985{ }^{\circ} \mathrm{C}$, and it solidifies below $943^{\circ} \mathrm{C}$ under the experimental conditions used in this study. The temperature of solid transformation of the metastable constituent to $\mathrm{Ni}_{3} \mathrm{~B}$ and $\mathrm{Ni}$ is strongly dependent on the amount of $\mathrm{Ni}_{3} \mathrm{~B}$ formed during solidification. The minimal temperature of such transformation, $834{ }^{\circ} \mathrm{C}$, corresponds to samples where $\mathrm{Ni}_{3} \mathrm{~B}$ solidification was not detected in the thermal curves.
\end{abstract}

Keywords: thermal analysis; microstructure; metastable phase

\section{Introduction}

For traditional industrial applications, nickel base alloys are of great importance because they can be used in a wide range of severe operating conditions, since these alloys stand out for their corrosion resistance, high-temperature wear resistance, and combinations of these properties [1]. When high-temperature wear resistance is required, so-called hardened alloys consisting of a ductile metal matrix (nickel) and hard phases, such as carbides, borides, and silicides, can be used [2]. This kind of alloy results in combined properties that are of interest for the manufacture of molds, especially for the glass industry [3,4]. For this application, Ni-B and Ni-B-Si alloys are remarkable, though they are also of interest to other important research fields. These alloys have been studied in view of such applications as bulk glassy alloys [5-7] soft magnetic materials [8], or brazing filler alloys [9-11].

Ni-B-Si alloys, with addition of elements as C, Cr, and Fe, are developed for hardfacing of critical components in nuclear plants exposed to wear $[12,13]$. In general, the structure of these alloys consists of Ni dendrites and interdendritic eutectics comprised of Ni plus Ni-borides and nickel silicides [14]. 
Presence of Ni borides or nickel silicides can be tailored by weight ratio of $\mathrm{Si}$ to $\mathrm{B}$ : a Si/B weight ratio

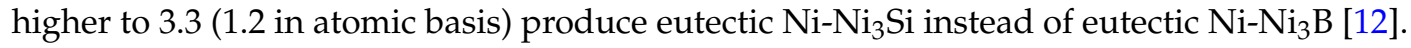

Silicon addition is also important because this element, as well as boron, provides self-fluxing properties and influences the wear properties. Silicon and boron reduce Ni oxides [15], forming low-density oxides that float [16] conferring to this alloy the self-flux characteristic. Among self-fluxing alloys, the nickel-base alloys containing 1-3 wt. \% ep of B and 2.3-5 wt. \% Si are widely used. Silicon increases hardness that results in an increase on wear resistance [12], as an increase in boron content also does [12]. Several hardfacing Ni based alloys contain $\mathrm{Si}$ as an alloying element [12-14,17]. The addition of $\mathrm{Si}$ and $\mathrm{B}$ increase also the solidification interval of alloy [1].

In order to use Ni-Si-B alloys to produce molds for the glass industry, the composition range that allows the formation of a matrix composed by pre-eutectic Ni dendrites is a main concern, in order to obtain a material with a good compromise between toughness and hardness. According to Tanaka [12], toughness and ductility of an alloy is essentially determined by toughness and ductility of the matrix. $\mathrm{Ni}$ dendrites are tough and ductile [18] so it is suitable to have a matrix composed by Ni dendrites if toughness is required for a specified application of Ni-B-Si alloys. Matrix of Ni dendrites is also observed in hardfacing alloys [12-14,17]. Ternary diagram of the Ni-Si-B systems, such as the one reported by Lebailli et al. [19], allows to choose the alloys composition that could have $\mathrm{Ni}\left(\mathrm{fcc}_{\mathrm{c}}\right)-\mathrm{Ni}_{3} \mathrm{~B}$ or $\mathrm{Ni}(\mathrm{fcc})-\mathrm{Ni}_{3} \mathrm{Si}$ eutectics with pre-eutectic $\mathrm{Ni}(\mathrm{fcc})$. This latter constituent has a dendritic morphology, which is characterized by the secondary dendrite arm space, SDAS. In metallic alloys, it is known that mechanical properties are improved when the SDAS is reduced. The SDAS determines the spacing of secondary constituents and thus has a considerable effect upon the mechanical properties of as-cast alloys [20,21]. The SDAS value is reduced as solidification time is reduced or as cooling rate increases [20].

In all these fields, knowledge about the solidification mechanism of Ni-B-Si alloys is a common interest. Information about solidification on Ni-B binary alloys is more abundant than that on Ni-B-Si alloys. According to the binary diagram, alloys with a composition below 30 at. \% B can have two constituents at room temperature, $\mathrm{Ni}(\mathrm{fcc})$ and eutectic $\mathrm{Ni}(\mathrm{fcc})-\mathrm{Ni}_{3} \mathrm{~B}$, such that during solidification and subsequent cooling, it is expected that only two reactions peaks would be observed in the cooling curves. However, because of the difficulty for $\mathrm{Ni}_{3} \mathrm{~B}$ nucleation, more than two thermal reaction peaks can be observed in the cooling curves, since a metastable phase appears during solidification. Ajao et al. [4] found that three reactions occur during cooling in the differential thermal analysis (DTA) of nickel alloys with a boron content below 30 at. \%. They attribute the third reaction to a possible solid-state transformation of a hypothetical $\mathrm{Ni}_{3} \mathrm{~B}$ phase oversaturated with nickel. Baricco et al. [22] also report three peaks in the differential scanning calorimeter (DSC) curves. They proposed that the second reaction observed during solidification corresponds to the formation of the $\mathrm{Ni}_{23} \mathrm{~B}_{6}$ phase that subsequently undergoes transformation into $\mathrm{Ni}_{3} \mathrm{~B}$. They associated this transformation to the third reaction peak in the thermal analysis curves. $\mathrm{Xu}$ et al. $[23,24]$ observed two or three recalescence peaks in the cooling curves. When this behavior occurs, they proposed that $\mathrm{Ni}_{23} \mathrm{~B}_{6}$ metastable phase appears, according to the results of Baricco et al. [22]. For their experiments, $\mathrm{Xu}$ et al. [24] use a special procedure consisting of remelting samples of a Ni-15.6 at. \% $\mathrm{B}$ alloy under $\mathrm{B}_{2} \mathrm{O}_{3}$ glass in an apparatus for glass fluxing experiments.

Several propositions have been made for the crystallographic state of the metastable phase formed during the solidification of $\mathrm{Ni}-<30$ at. $\% \mathrm{~B}$ alloys: an $\mathrm{Ni}_{3} \mathrm{~B}$ phase oversaturated with $\mathrm{Ni}$ [4], an $\mathrm{Ni}_{5} \mathrm{~B}_{2}$ phase in rapidly quenched $\mathrm{Ni}-25$ at. \% $\mathrm{B}$ samples obtained by the melt spun technique [3], a metastable $\mathrm{Ni}_{2} \mathrm{~B}$ phase at $\mathrm{B}$ contents lower than 20 at. \% [2] and $\mathrm{Ni}_{23} \mathrm{~B}_{6}$ [22]. M. Baricco et al. [22] obtained the $\mathrm{X}$-ray diffraction pattern of a Ni-18.7 at. \% B alloy quenched during cooling in a high-temperature differential scanning calorimeter (HT-DSC). Nevertheless, the cubic crystalline parameters of the $\mathrm{Ni}_{23} \mathrm{~B}_{6}$ phase were not reported by these authors, and as such, comparison with values found in the open literature is not possible. 
Formation of a metastable phase allows a wide variation in microstructure to be observed on solidified samples of Ni- $<30$ at. \% B alloys, as noted by Ajao et al. [4] and $\mathrm{Xu}$ et al. [25]. This variety of microstructural features has also been found in Ni-B systems with added Si and/or Cr. According to Knotek et al. [2] and J. Ajao et al. [4], the solidification of alloys that they studied follows a behavior similar to that observed for Ni-B binary alloys.

All authors cited previously here [2-4,22], agree that during the solidification of Ni-B alloys with $\mathrm{B}$ contents lower than 20 at. \%, a Ni $\mathrm{B}_{y}$ metastable phase could appear. Baricco et al. [22] suggests that this metastable phase could be the $\mathrm{Ni}_{23} \mathrm{~B}_{6}$ phase, but the crystallography of this phase still needs to be confirmed by other studies. Another common feature of these studies is that special techniques were used to obtain the studied samples, using powders of high-purity materials that were arc-melted in an argon atmosphere with a non-consumable tungsten electrode [4,23-26] or by melt spinning [3]. Since nucleation is enhanced by solid impurities that may appear in standard casting practices, the question arises if these special melting procedures could lead to solidification in the metastable system.

This research was performed to complement knowledge on the microstructural development of the Ni-10.95 at. \% B-3.23 at. \% Si alloy, used for the manufacture of molds in the glass industry. Particularly, the focus of this work was to elucidate the susceptibility of this alloy to solidify in a metastable system, by using samples from a cast alloy obtained through typical industrial procedures. In addition, the possibility that the $\mathrm{Ni}_{23} \mathrm{~B}_{6}$ phase may appear and its mechanism of solidification were analyzed by thermal analysis, along with microstructural features of the remelted samples and thermodynamic simulations.

\section{Materials and Methods}

The nickel base alloy was obtained by melting proper quantities of electrolytic nickel, Ni-57.5 at. \% $B$ and silicon metal, in an induction furnace. All materials were of industrial-grade purity. The molten alloy was poured into an investment mold pre-heated at $850{ }^{\circ} \mathrm{C}$. The pattern mold was designed to obtain cast bars $25 \mathrm{~cm}$ in length. Twenty-four bars had diameters of $0.65 \mathrm{~cm}$, and eight bars had diameters of $0.9 \mathrm{~cm}$. The weight of the casting, including runners and risers, was $8 \mathrm{~kg}$.

To obtain cooling curves from the poured metal, two industrial cups for thermal analysis were poured, and their cooling curves registered with a temperature data logger portable device from Ahlborn Equipment, Munich, Germany. The cups, from Heraeus Electro-Nite, correspond to models QC410_QK100 and QC4000COV, and they were chosen to obtain different cooling rates, the latter one allows a higher cooling rate than the former one.

Chemical analysis of the casting was obtained by inductively coupled plasma-atomic emission spectroscopy (ICP), except for sulfur and carbon, which were analyzed by the Leco technique. The alloy composition, shown in Table 1, is close to a ternary alloy, which will be referred to from here on out as the Ni-10.95 at. \% B-3.23 at. \% Si alloy.

Table 1. Chemical composition of the nickel base alloy (at. \%). Composition calculated from results in weight basis.

\begin{tabular}{ccccccccc}
\hline $\mathbf{B}$ & $\mathbf{S i}$ & $\mathbf{F e}$ & $\mathbf{C r}$ & $\mathbf{A l}$ & $\mathbf{T i}$ & $\mathbf{C}$ & $\mathbf{S}$ & $\mathbf{N i}$ \\
\hline 10.945 & 3.228 & 0.030 & 0.020 & 0.062 & 0.002 & 0.074 & 0.015 & Balance \\
\hline
\end{tabular}

For thermal analysis of the remelted samples, both DSC and an in-house apparatus for controlled-temperature programing were employed. For the former, samples under $200 \mathrm{mg}$, extracted from the thin bars, were placed into alumina crucibles and then heated in a scanning differential calorimeter, (DSC-TGA Standard model SDT Q600, TA Instruments, New Castle, DE, USA), using an empty crucible as the reference sample. The heating was from room temperature to $1400{ }^{\circ} \mathrm{C}$ at rates of $5,10,15$, or $20^{\circ} \mathrm{C} / \mathrm{min}$. After that, the samples were cooled to $25^{\circ} \mathrm{C}$ at the same rates used in the corresponding heating cycle. A $100 \mathrm{~mL} / \mathrm{min}$ argon flux was used throughout the thermal cycle. 
Additionally, in some experiments, cooling was interrupted at $900{ }^{\circ} \mathrm{C}$, and the sample was reheated to $1400{ }^{\circ} \mathrm{C}$ in order to obtain the melting temperature of the metastable constituent. For the cooling curve technique (CCT) experiments, $18 \mathrm{~g}$ samples extracted from the thick bars were remelted and then solidified under Ar atmosphere in an in-house thermal analysis apparatus, see Figure 1. These samples were placed into an alumina crucible and then heated to $1400^{\circ} \mathrm{C}$, held at this temperature for $5 \mathrm{~min}$ and cooled at the same cooling rates as employed in the DSC experiments. The thermal curves were recorded with a B thermocouple connected to a data acquisition card (Omega OMB DaqTemp model 7 and DaqView software version 9.1.27 (National Instruments Corporation, Austin, TX, USA).

For metallographic preparation of the processed samples, a procedure according to the ASTM E3-11 standard was employed. The polished samples were slightly etched with $5 \mathrm{~g} \mathrm{FeCl}_{3}$ plus $10 \mathrm{~mL}$ $\mathrm{HCl}$ dissolved in $50 \mathrm{~mL} \mathrm{H} \mathrm{H}_{2} \mathrm{O}$, after which the microstructure was examined by optical microscopy (Nikon, Tokyo, Japan).

To identify phases in the samples at room temperature, X-ray diffraction was performed for several bulk samples. XRD measurements were performed on a PANalytical X-ray diffractometer, model EMPYREAN (PANalytical, Almelo, The Netherlands). The measurements were performed during 36,034 s, from 20 to 80 degree with a pitch size of 0.026 degree, using $\mathrm{Cu}-\mathrm{K} \alpha$ incident radiation with a nickel filter. To index XRD pattern peaks, all phases expected according to main constituents from chemical composition and with available JCFDS cards were tested. The JCFDS cards for $\mathrm{Ni}_{23} \mathrm{~B}_{6}$, that were tested to index XRD peaks were the 01-073-7324 and the 01-074-3232, both considered in hypothetic quality. The JCFDS cards that applied to index the diffractograms were 03-065-2865 and 01-082-1699 that correspond to $\mathrm{Ni}$ and $\mathrm{Ni}_{3} \mathrm{~B}$, respectively.

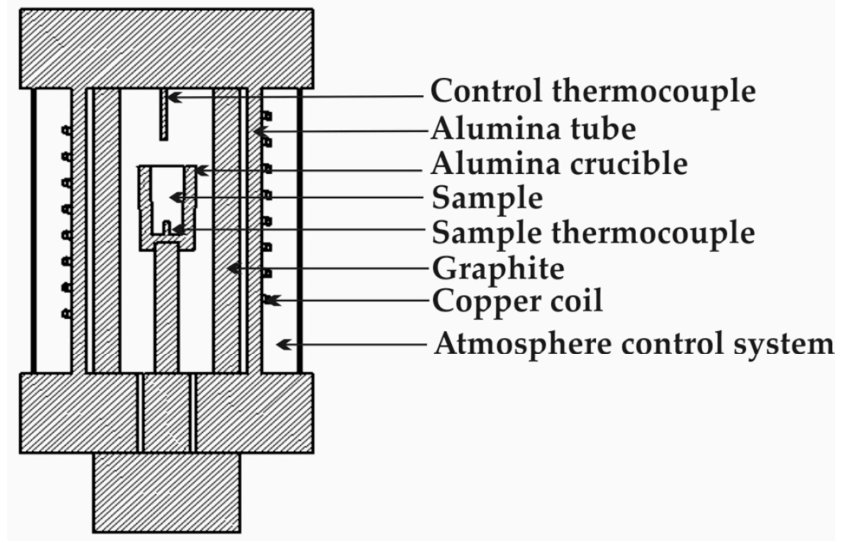

Figure 1. In-house thermal analysis apparatus.

\section{Results and Discussion}

\subsection{Thermal Curves and Microstructure}

Thermal curves show different combinations of disturbances. According to its characteristics, each disturbance was associated with a reaction and labeled as shown in Table 2. Note that the subscripts $m$ and $\mathrm{s}$ were added to indicate if the reaction was identified during melting or solidification.

Table 2. Nomenclature of the disturbances according to the reactions with which they were associated.

\begin{tabular}{cc}
\hline Reaction & Description \\
\hline $\mathrm{R} 1_{\mathrm{m}}$ or $\mathrm{R} 1_{\mathrm{s}}$ & Melting or solidification of nickel. \\
$\mathrm{R} 2_{\mathrm{m}}$ or $\mathrm{R} 2_{\mathrm{s}}$ & Melting or solidification of the stable constituent of eutectic $\mathrm{Ni}-\mathrm{Ni}_{3} \mathrm{~B}$. \\
$\mathrm{R} 3_{\mathrm{m}}$ or $\mathrm{R} 3_{\mathrm{s}}$ & Melting or solidification of the metastable $\mathrm{Ni}_{x} \mathrm{~B}_{y}$ alone or as part of a eutectic constituent. \\
$\mathrm{R} 4$ & Solid-state transformation of the $\mathrm{Ni}_{x} \mathrm{~B}_{y}$ constituent to Ni-Ni${ }_{3} \mathrm{~B}$ stable constituents. \\
\hline
\end{tabular}




\subsection{Heating}

Thermal peaks at $1100{ }^{\circ} \mathrm{C}$ and $1212{ }^{\circ} \mathrm{C}$ were identified in the DSC experiments during heating from room temperature to $1400{ }^{\circ} \mathrm{C}$. The former was associated with $\mathrm{R} 2 \mathrm{~m}$, and the latter with $\mathrm{R} 1_{\mathrm{m}}$, see Figure 2.

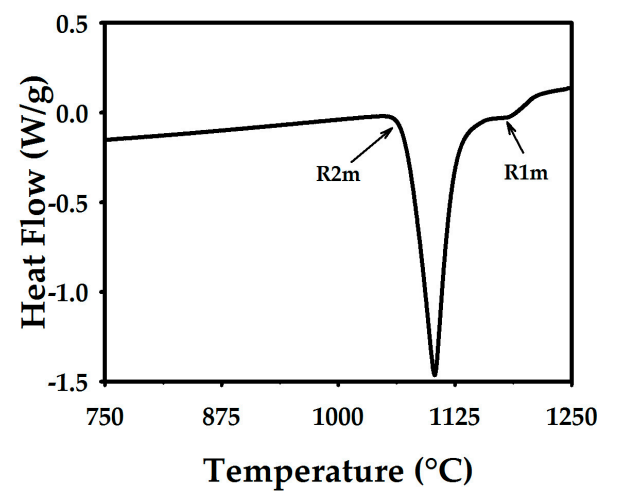

Figure 2. DSC heating curve corresponding to the Ni-10.95 at. \% B-3.23 at. \% Si alloy heated at $5{ }^{\circ} \mathrm{C} / \mathrm{min}$.

The onset temperature and peak temperature of the $\mathrm{R} 2 \mathrm{~m}$ peak provide an idea of the temperature range in which the stable eutectic transformation occurs in the Ni-10.95 at. \% B-3.23 at. \% Si alloy. In fact, this temperature range will be larger than that based on thermodynamic considerations, because of bias introduced by phenomena such as transformation kinetics, thermal lag and microsegregation, as reviewed by Boettinger et al. [27]. The temperatures were determined from the DSC curves according to the ASTM E967 standard. Table 3 shows the average values of both temperatures and the corresponding values obtained by thermodynamic simulation. It is observed that, as expected, the temperature range for the eutectic transformation provided by experiments $\left(T_{\text {onset }}-T_{\text {peak }}\right), 30^{\circ} \mathrm{C}$, is larger than the corresponding range obtained by simulation using lever rule $\left(T_{\text {ini }}-T_{\text {end }}\right), 3{ }^{\circ} \mathrm{C}$. However, the temperature range obtained by simulation using the Scheil-Gulliver model, $39^{\circ} \mathrm{C}$, is larger than the experimental range. This indicates the importance of microsegregation in the temperature range for eutectic reaction. In Table 3, it is also observed that the peak temperature is both equal to that reported by Ajao et al., $1100{ }^{\circ} \mathrm{C}$, [4] and lower than the initial temperature of eutectic transformation obtained by simulation using lever rule, $1128^{\circ} \mathrm{C}$. This last feature is opposite to that expected from experiments bias. This inconsistence could arise from a lack of data precision in the thermodynamic calculations. Average values of both the onset temperature and peak temperature of the $\mathrm{R} 2 \mathrm{~m}$ peak will be taken as a reference for the analysis of microstructural transformations during cooling. The $\mathrm{R} 2 \mathrm{~m}$ peak temperature will be labeled $T_{\text {eut }}$ hereafter.

Table 3. Temperatures corresponding to the $\mathrm{R} 2 \mathrm{~m}$ peak.

\begin{tabular}{clc}
\hline $\mathbf{R} \mathbf{2}_{\mathbf{m}}\left({ }^{\circ} \mathbf{C}\right)$ & \multicolumn{1}{c}{ Comments } & Reference \\
\hline $\begin{array}{c}T_{\text {onset }}=1070 \pm 2{ }^{\circ} \mathrm{C} \\
T_{\text {peak }}=1100 \pm 4{ }^{\circ} \mathrm{C}\end{array}$ & $\begin{array}{l}\text { Ni-10.95 at. \% B-3.23 at. \% Si alloy. } \\
\text { Average of } 21 \text { data points from peaks } \\
\text { observed during heating. }\end{array}$ & This study. \\
\hline$T=1100{ }^{\circ} \mathrm{C}$ & Ni-16.2 at. \% B-1 at. \% Si, during heating. & {$[4]$} \\
\hline$T_{\text {ini }}=1128^{\circ} \mathrm{C}$ & $\begin{array}{l}\text { Ni-10.95 at. \% B-3.23 at. \% Si alloy. } T_{\text {ini }} \text { and } \\
T_{\text {end }} \text { are the initial and final temperatures } \\
\text { for eutectic reaction, respectively. }\end{array}$ & $\begin{array}{c}\text { ThermoCalc simulation with TCNI5 } \\
\text { database data, lever rule. }\end{array}$ \\
\hline$T_{\text {ini }}=1125^{\circ} \mathrm{C}$ & Ni-10.95 at. \% B-3.23 at. \% Si alloy. & $\begin{array}{c}\text { ThermoCalc simulation with TCNI5 } \\
\text { database data, Scheil-Gulliver model with } \\
\text { activated option of fast diffusing elements. }\end{array}$ \\
\hline
\end{tabular}


When the samples were heated from room temperature to their melting temperature, $R 3_{m}$ was not observed. To evidence the existence of $\mathrm{R} 3_{\mathrm{m}}$ several experiments were conducted by interrupting cooling at $900{ }^{\circ} \mathrm{C}$ followed by reheating (2nd heating) to $1400{ }^{\circ} \mathrm{C}$. When $\mathrm{R} 3 \mathrm{~m}$ was detected, no additional disturbances were observed in the previous $\mathrm{R} 3_{\mathrm{s}}$ peak, as shown in Figure 3a. If during cooling any disturbance appears in the $\mathrm{R} 3_{\mathrm{s}}$ peak, then $\mathrm{R} 3_{\mathrm{m}}$ is considered to not be observed during reheating, see Figure 3b. It is observed in this figure that a perturbation appears in the $\mathrm{R} 3_{\mathrm{s}}$ peak, and as a consequence, in the subsequent reheating, $\mathrm{R} 2 \mathrm{~m}$ appears instead of $\mathrm{R} 3 \mathrm{~m}$. According to the thermal curve evidence and the microstructural features (to be presented later), the additional perturbation of the $\mathrm{R} 3_{\mathrm{s}}$ peak is associated with both reactions $\mathrm{R} 2_{\mathrm{s}}$ and $\mathrm{R} 4$. It is hypothesized that the latter reaction occurs because the nucleation barrier for $\mathrm{Ni}_{3} \mathrm{~B}$ was overcome. Then, the possibility to observe $\mathrm{R} 3_{\mathrm{m}}$ strongly decreases when $\mathrm{R} 2_{\mathrm{s}}$ and $\mathrm{R} 4$ occur in the early stages of solidification.
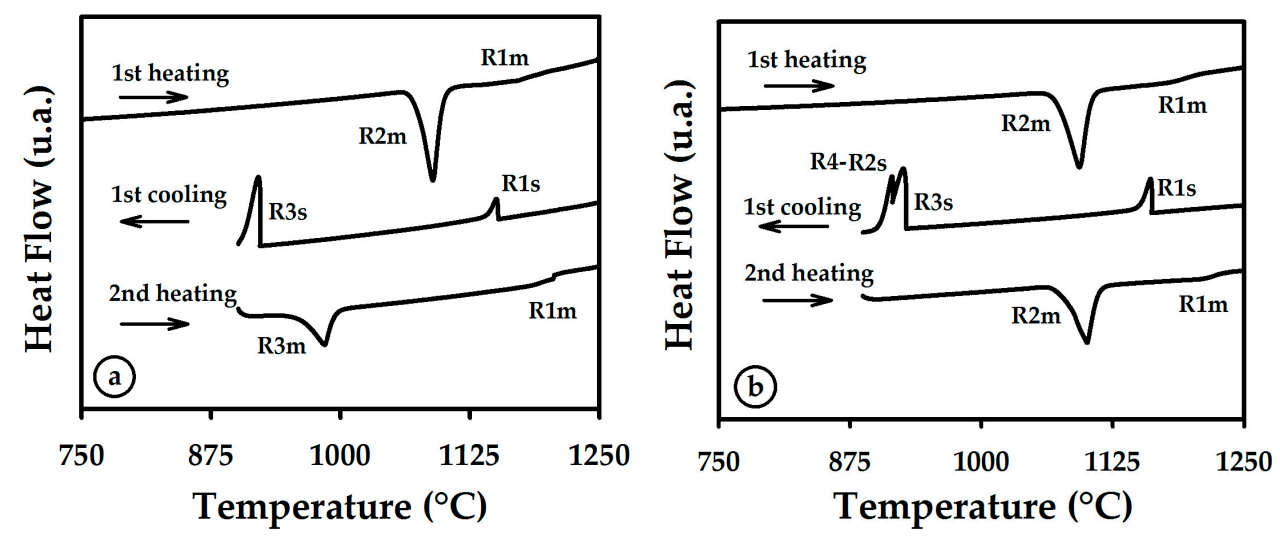

Figure 3. DSC thermal curves showing reheating (second heating) to $1400{ }^{\circ} \mathrm{C}$ after cooling was interrupted at $900{ }^{\circ} \mathrm{C}$. Samples of the Ni-10.95 at. \% B-3.23 at. \% Si alloy with cooling and heating rates of $10^{\circ} \mathrm{C} / \mathrm{min}$ : (a) detection of $\mathrm{R} 3 \mathrm{~m}$ and (b) detection of $\mathrm{R} 2 \mathrm{~m}$.

The onset and peak temperatures corresponding to the $\mathrm{R} 3_{\mathrm{m}}$ peak are $960{ }^{\circ} \mathrm{C}$ and $985{ }^{\circ} \mathrm{C}$, respectively. This peak temperature is very close to the $988{ }^{\circ} \mathrm{C}$ temperature reported by Baricco et al. [22] for the melt temperature of the metastable constituent in the binary Ni-B alloy. They obtained this value from a peak observed during reheating.

\subsection{Cooling}

Thermal curves during cooling show a higher number of disturbances compared to the number observed during heating. The maximal number of peaks, four, was observed only in some DSC curves, due to the higher sensitivity of this technique compared with the one cooling curve technique (CCT).

Regardless of the observed number of reactions during cooling, the X-ray diffractograms collected for several samples at room temperature show only two constituents, $\mathrm{Ni}$ and $\mathrm{Ni}_{3} \mathrm{~B}$, as seen in the diffractograms in Figure 4. In this figure, one diffractogram corresponds to a sample with the reaction sequence $R 1_{s}-R 2_{s}$, and the other corresponds to a sample with the sequence $R 1_{s}-R 3_{s}-\left(R 2_{s}-R 4\right)$. In Figure 4, a difference in the intensity of the Ni X-ray peaks is also observed. This difference is related to the solidification texture present in the analyzed solid samples. The difference in the X-ray peaks of the $\mathrm{Ni}_{3} \mathrm{~B}$ compound are fewer than those observed in the corresponding Ni peaks. This may arise from the fact that the grain size of constituents that contain borides is smaller than that of Ni grains, as inferred from the microstructures of the samples shown later. 


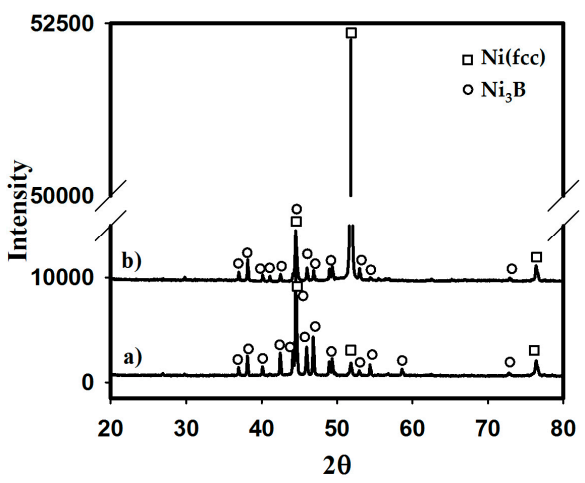

Figure 4. X-ray diffractograms of the Ni-10.95 at. \% B-3.23 at. \% Si samples at room temperature that show different reaction sequences in the CCT thermal curves: (a) $R 1_{s}-R 2_{s}$ and (b) $R 1_{s}-R 3_{s}-\left(R 2_{s}-R 4\right)$. Both samples were obtained at $5^{\circ} \mathrm{C} / \mathrm{min}$ cooling rate.

The number, sequence and temperature of the reactions observed during cooling has a great effect on the microstructural morphology of the samples. Figure 5 shows the microstructure of a sample extracted from the initial casting, in which the solidification sequence $R 1_{s}-R 2_{s}$ is expected.

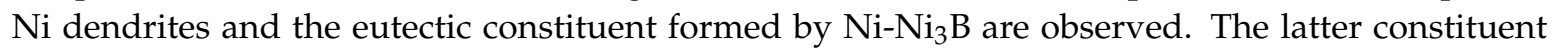
shows two morphologies: a laminar eutectic and a so-called anomalous eutectic structure $[23,28]$.

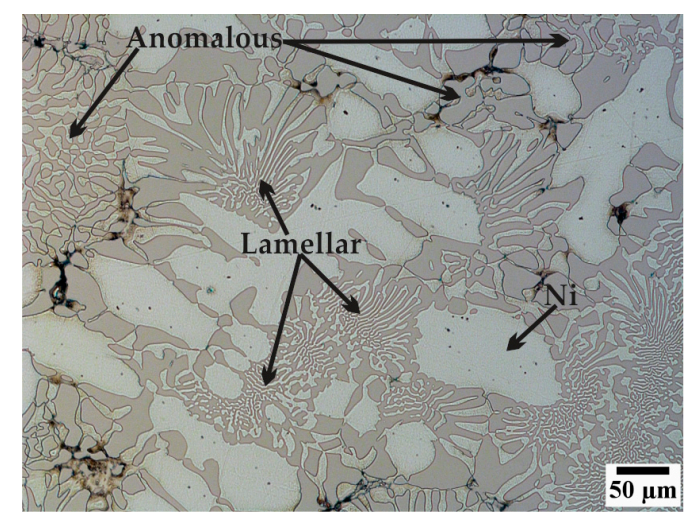

Figure 5. As-cast microstructure of the Ni-10.95 at. \% B-3.23 at. \% Si alloy in a bar that is $0.9 \mathrm{~cm}$ in diameter.

Figure 6 shows the curves and microstructures observed for the thermal analysis cups poured during casting of the bars. The microstructural features are similar to those observed in the casting bars. Comparison between the microstructure of the thermal cups reveals a difference in its fineness. This difference is related to changes in the cooling rate; the fineness of the microstructure increases when the cooling rate is augmented. The maximal temperature of the eutectic plateau is similar in both thermal curves, $1078-1079{ }^{\circ} \mathrm{C}$, i.e., an undercooling of $21-22{ }^{\circ} \mathrm{C}$ with respect to $T_{\text {eut }}, 1100{ }^{\circ} \mathrm{C}$.

When the reaction sequence $\mathrm{R} 1_{\mathrm{s}}-\mathrm{R} 2_{\mathrm{S}}$ is observed and $\mathrm{R} 2_{\mathrm{s}}$ appears at a temperature of approximately $944{ }^{\circ} \mathrm{C}$, or eutectic undercooling near $156{ }^{\circ} \mathrm{C}$, the anomalous eutectic structure is only observed, as shown in Figure 7c,d. This result agrees with the findings in previous works, where it was observed that the volume fraction of the anomalous eutectic phase increases when undercooling of the eutectic reaction increases in the binary Ni-B system [23] and in other eutectic systems in binary alloys, such as Ag-Cu $[29,30]$ and Ni-P [30]. An important feature of the $\mathrm{R} 1_{\mathrm{s}}-\mathrm{R} 2_{\mathrm{s}}$ reaction sequence observed at high eutectic undercooling is that $\mathrm{R} 2_{\mathrm{s}}$ presents a high recalescence: $15^{\circ} \mathrm{C}$ and $60{ }^{\circ} \mathrm{C}$ in the DSC and CCT experiments, respectively. This recalescence is observed in the thermal curves shown in Figure $7 a, b$. 

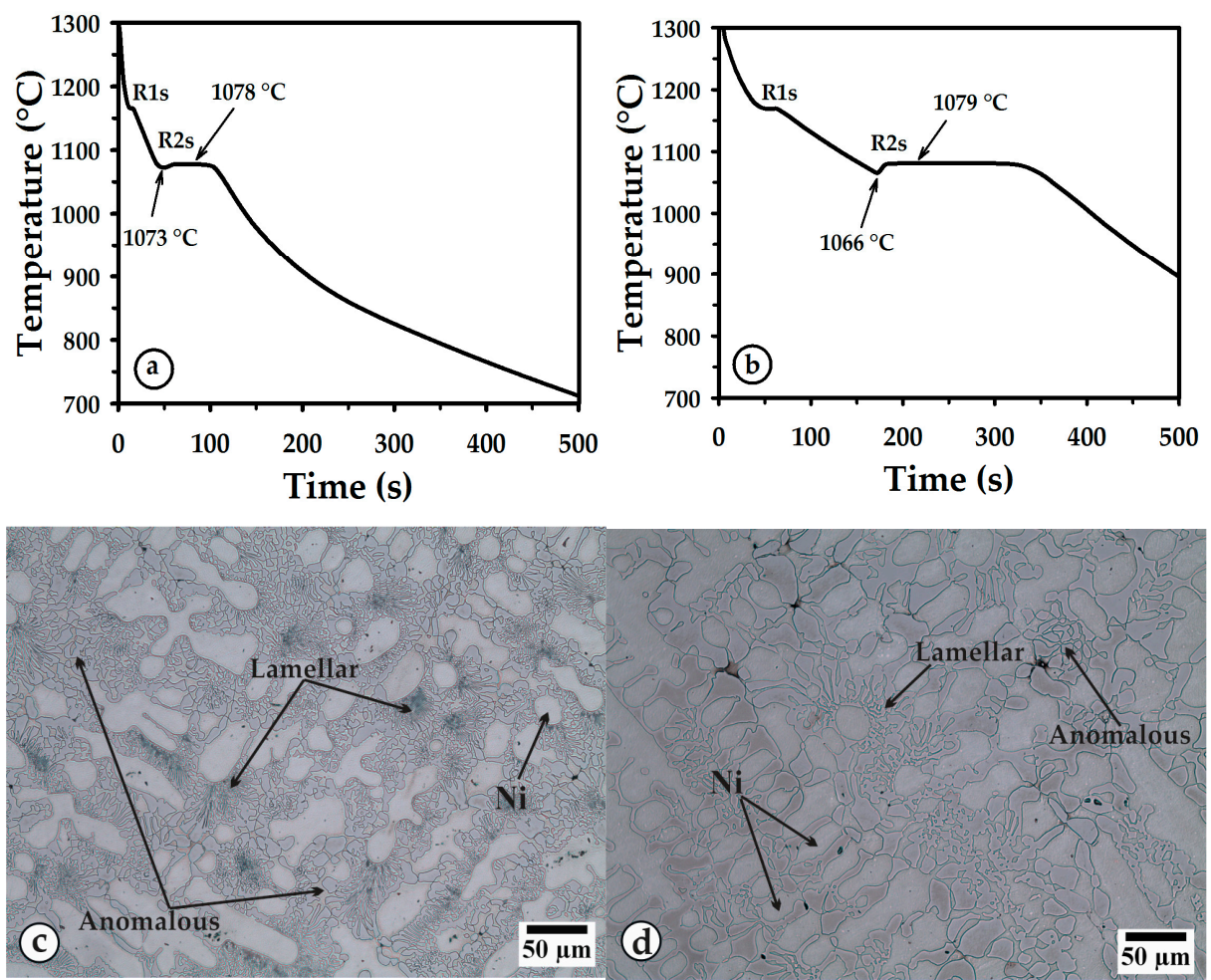

Figure 6. Thermal curves and as-cast microstructures of the Ni-10.95 at. \% B-3.23 at. \% Si alloy, observed in samples poured in thermal cups: $(\mathbf{a}, \mathbf{c})$ higher cooling rate (QC4000COV) and $(\mathbf{b}, \mathbf{d})$ lower cooling rate (QC4010_QK100).
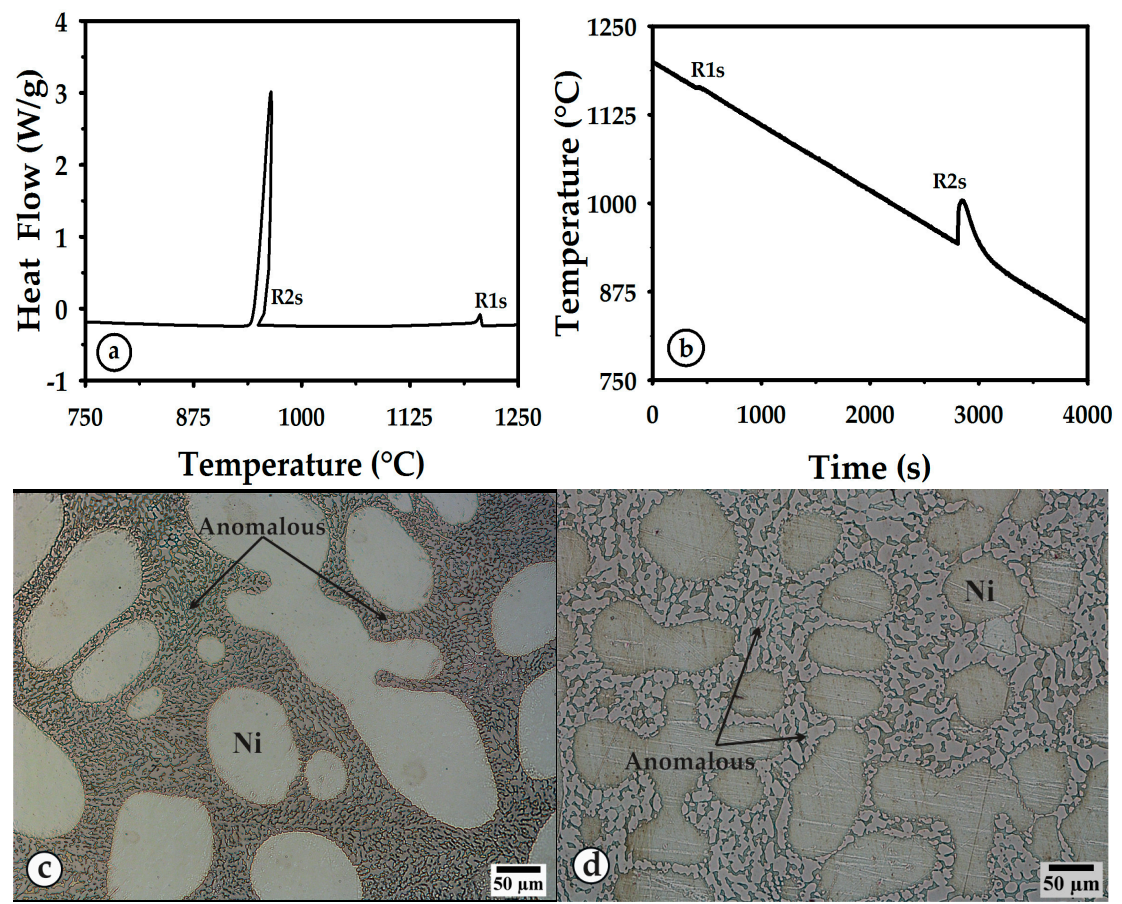

Figure 7. Thermal curves and microstructures corresponding to samples showing the $\mathrm{R} 1_{\mathrm{s}}-\mathrm{R} 2_{\mathrm{s}}$ reaction sequence in the Ni-10.95 at. \% B-3.23 at. \% Si alloy: (a,c) from DSC at a $10{ }^{\circ} \mathrm{C} / \mathrm{min}$ rate and $(\mathbf{b}, \mathbf{d})$ from $\mathrm{CCT}$ at a $5{ }^{\circ} \mathrm{C} / \mathrm{min}$ cooling rate. 
When onset temperature of the eutectic reaction is below $944{ }^{\circ} \mathrm{C}$, several reaction sequences were observed in the DSC curves, leading to important microstructural changes. At such temperatures, $\mathrm{R} 3_{\mathrm{s}}$ or the metastable constituent appears before $\mathrm{R} 2_{\mathrm{s}}$, and the latter can even disappear.

The extreme case where $\mathrm{R} 2_{\mathrm{s}}$ disappears assists to illustrate the microstructure resulting from the solidification of the metastable constituent and its subsequent transformation to the stable constituent. Figure $8 \mathrm{a}$ shows a DSC curve with an $\mathrm{R} 1_{\mathrm{s}}-\mathrm{R} 3_{\mathrm{s}}-\mathrm{R} 4$ sequence, and the microstructure of the corresponding sample is shown in Figure $8 \mathrm{~b}$. This microstructure shows a fibrous constituent and coarse zones of nickel boride with small embedded dots. These small dots are better appreciated in Figure 13b. Besides the fact that this microstructure is quite different from that observed for $\mathrm{R} 1_{\mathrm{s}}-\mathrm{R} 2_{\mathrm{s}}$ reaction sequence, the question arises if the fibrous constituent is formed during solidification or during solid-state transformation. $\mathrm{Xu}$ et al. [23] relate the formation of regularly distributed dots, called fibrous constituents here, to a eutectic reaction. This hypothesis is analyzed in the next paragraphs with the support of additional thermal and microstructural evidence.
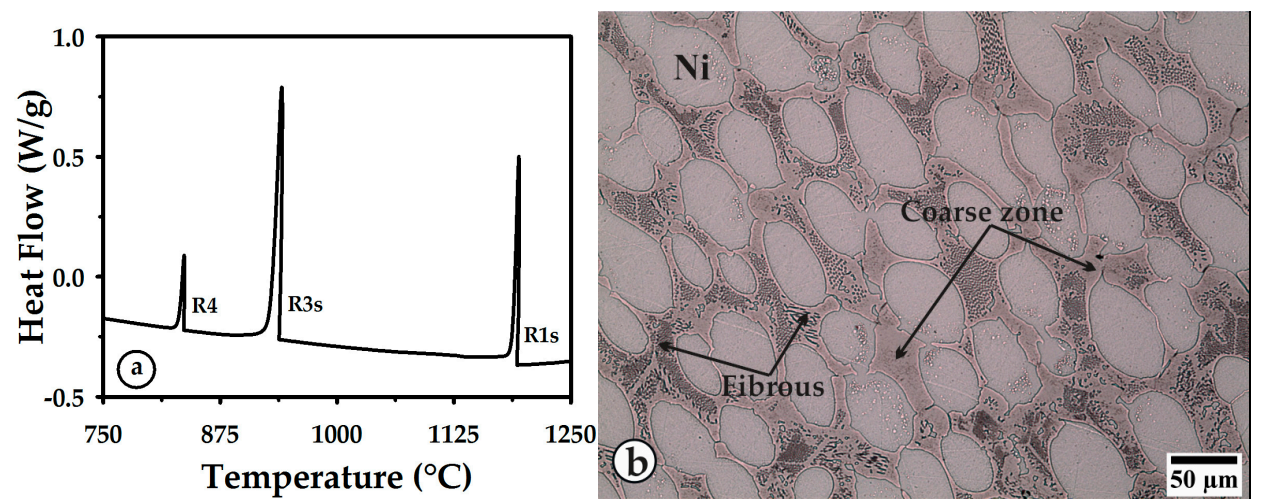

Figure 8. (a) Thermal curve and (b) microstructure corresponding to a sample of the Ni-10.95 at. \% B-3.23 at. \% Si alloy that showed the $\mathrm{R} 1_{\mathrm{s}}-\mathrm{R} 3_{\mathrm{s}}-\mathrm{R} 4$ reaction sequence without $\mathrm{R} 2 \mathrm{~s}$. The data correspond to a DSC experiment at a cooling rate of $5{ }^{\circ} \mathrm{C} / \mathrm{min}$.

When a sub-disturbance appears in the $\mathrm{R} 3_{\mathrm{s}}$ peak or on the metastable eutectic plateau, two reaction sequences can be identified, depending on the sub-disturbance location. If the latter appears during the initial stages of either the R3 s peak or the metastable eutectic plateau, see Figure $9 a, b$, then R4 is not observed as a unique peak. As the X-ray diffractograms show only stable constituents, R4 must be overlapped with the $\mathrm{R} 2_{\mathrm{s}}$ solidification reaction. In this case, the overall reaction sequence is noted as $R 1_{s}-R 3_{s}-\left(R 2_{s}-R 4\right)$. The sequence in parentheses means that $R 2_{s}$ is followed by overlapping of $R 4$. This hypothesized sequence $\left(\mathrm{R} 2_{\mathrm{s}}-\mathrm{R} 4\right)$ is based on the fact that the transformation of metastable $\mathrm{Ni}_{x} \mathrm{~B}_{y}$ must depend essentially on the nucleation of $\mathrm{Ni}_{3} \mathrm{~B}$. When the latter appears in appreciable quantity during solidification, then $\mathrm{Ni}_{x} \mathrm{~B}_{y}$ could easily begin to transform into $\mathrm{Ni}_{3} \mathrm{~B}$ and $\mathrm{Ni}$, as the nucleation barrier is overcome and a large amount of surface contact between the $\mathrm{Ni}_{3} \mathrm{~B}$ and $\mathrm{Ni}_{x} \mathrm{~B}_{y}$ phases is available. This circumstance occurs in the $R 1_{s}-R 3_{s}-\left(R 2_{s}-R 4\right)$ reaction sequence, where the important presence of $\mathrm{Ni}_{3} B$ as part of the anomalous eutectic is observed, see Figure $9 \mathrm{c}, \mathrm{d}$.

When the sub-disturbance appears during the last stage of the $\mathrm{R} 3_{\mathrm{s}}$ reaction, then the $\mathrm{R} 4$ peak appears, see Figure 10. In this case, the sub-disturbance in $R 3_{\mathrm{s}}$ is associated with $\mathrm{R} 2_{\mathrm{s}}$. The R4 peak may appear because even if the stable phase appears during the last solidification step, i.e., the nucleation barrier for $\mathrm{Ni}_{3} \mathrm{~B}$ is overcome, the surface contact of $\mathrm{Ni}_{x} \mathrm{~B}_{y}$ with $\mathrm{Ni}_{3} \mathrm{~B}$ is minimal, and thus the number of zones associated with the R4 reaction must be small; therefore, further undercooling is needed to boost the $\mathrm{R} 4$ reaction. The reaction sequence for this case is denoted $R 1_{s}-R 3_{s}-R 2_{s}-R 4$. It is worth mentioning that the sensitivity of the cooling curve technique (CCT) allows no detection of $R 2_{\mathrm{s}}$ if this reaction sequence occurs, as observed in Figure 10b. Therefore, the last peak in the CCT experiments was classified according to its onset temperature, which is related to the solidification step at which it 
occurs. Onset temperatures lower $901^{\circ} \mathrm{C}$ were associated with R4; otherwise, they were associated with $\left(R 2_{s}-R 4\right)$. Accordingly, the former case corresponds to the $R 1_{s}-R 3_{s}-R 2_{s}-R 4$ reaction sequence, while the later one to the $R 1_{s}-R 3_{s}-\left(R 2_{s}-R 4\right)$ reaction sequence. This criterion was validated by microstructural inspection performed in all CCT samples.
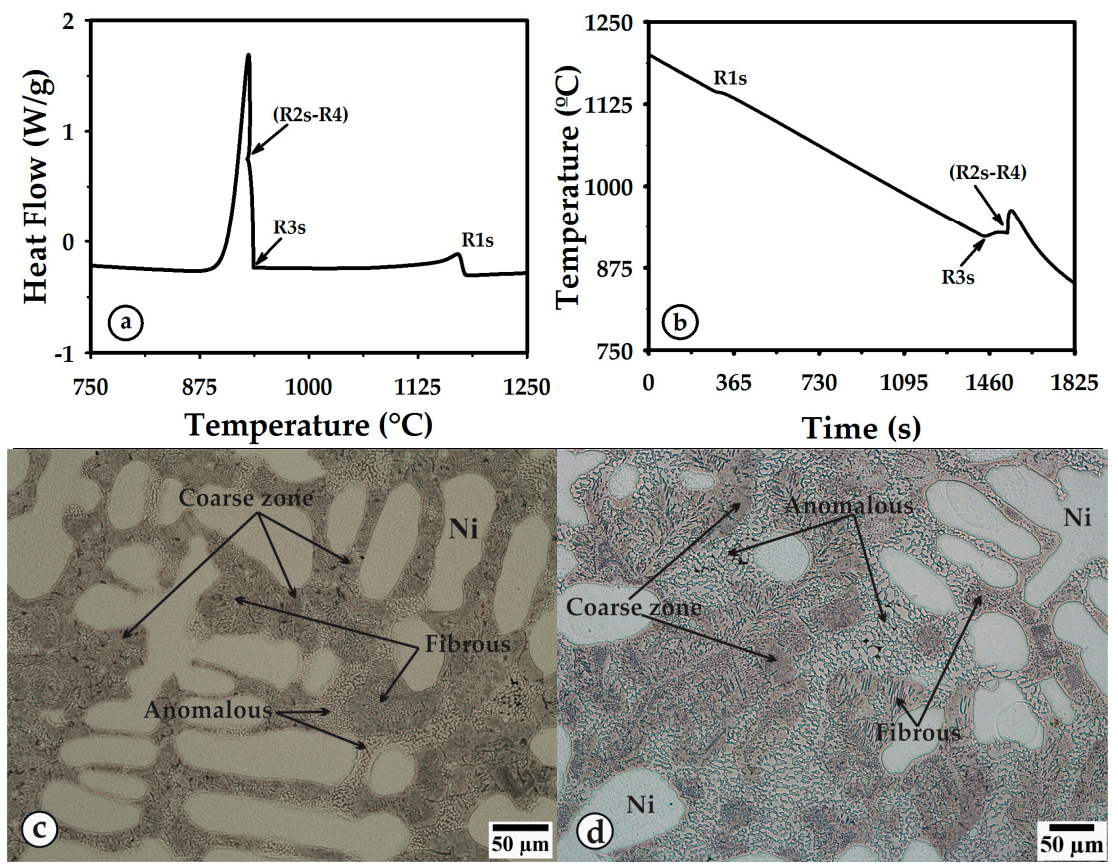

Figure 9. Thermal curves and microstructures corresponding to samples of the Ni-10.95 at. \% B-3.23 at. \% Si alloy that underwent the $\mathrm{R} 1_{\mathrm{s}}-\mathrm{R} 3_{\mathrm{s}}-\left(\mathrm{R} 2_{\mathrm{s}}-\mathrm{R} 4\right)$ reaction sequence: $(\mathrm{a}, \mathrm{c})$ from DSC at a $20{ }^{\circ} \mathrm{C} / \mathrm{min}$ cooling rate and $(\mathbf{b}, \mathbf{d})$ from $\mathrm{CCT}$ at a $10^{\circ} \mathrm{C} / \mathrm{min}$ cooling rate.
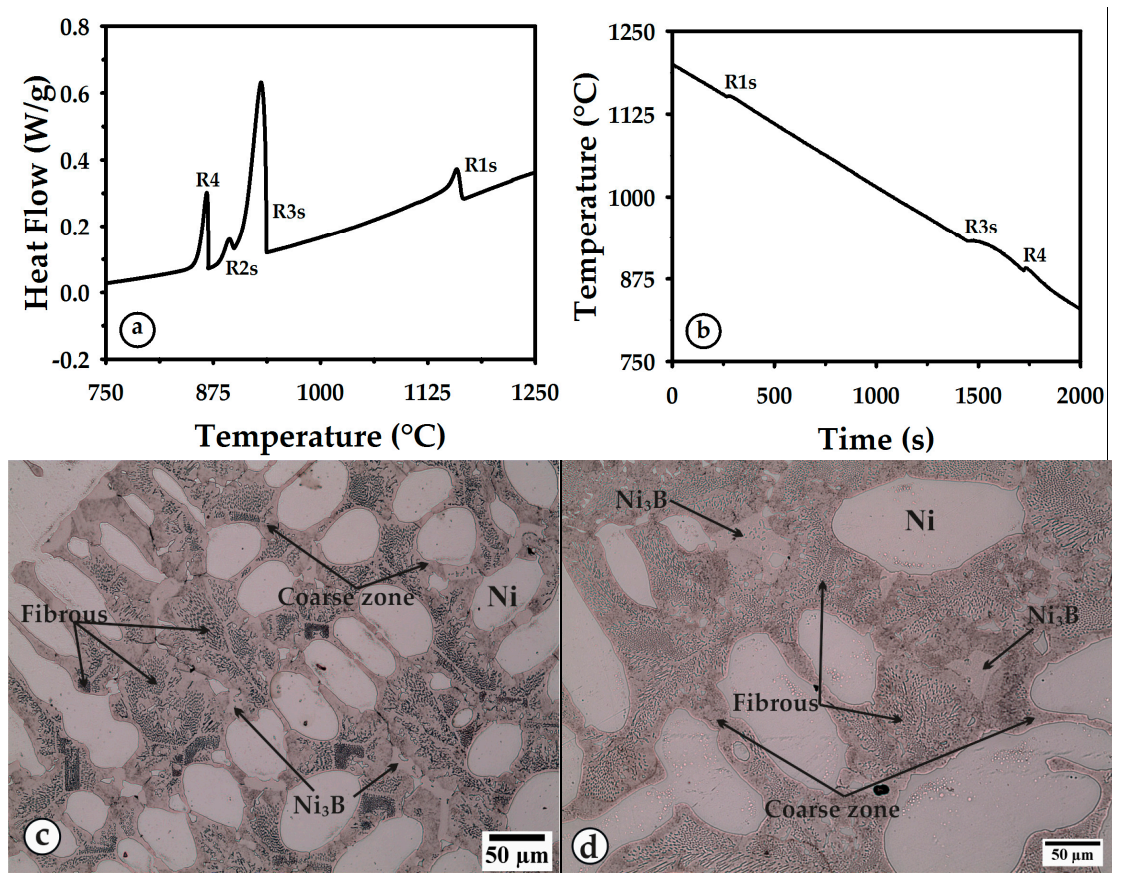

Figure 10. Thermal curves and microstructures corresponding to samples of the Ni-10.95 at. \% B-3.23 at. \% Si alloy that underwent the $\mathrm{R} 1_{\mathrm{s}}-\mathrm{R} 3_{\mathrm{s}}-\mathrm{R} 2_{\mathrm{s}}-\mathrm{R} 4$ reaction sequence: $(\mathrm{a}, \mathrm{c})$ from DSC at a $15^{\circ} \mathrm{C} / \mathrm{min}$ cooling rate and $(\mathbf{b}, \mathbf{d})$ from $\mathrm{CCT}$ at a $15{ }^{\circ} \mathrm{C} / \mathrm{min}$ cooling rate. 
The onset reaction temperatures obtained from the DSC data are shown in Figure 11, and the minimal temperatures, $T_{\min }$, of the reaction plateau observed from the CCT thermal curves are shown in Figure 12. In both figures, the data are grouped depending on the solidification sequence observed in the thermal curves, as confirmed by the microstructural analysis of several samples. In Figure 11, it is observed that most onset temperatures for $\mathrm{R} 1_{\mathrm{s}}$ are located in a temperature range of $1150^{\circ} \mathrm{C}$ to $1200^{\circ} \mathrm{C}$, while in Figure 12, it is observed that most of the $T_{\min }$ values are located in the $1130{ }^{\circ} \mathrm{C}-1170{ }^{\circ} \mathrm{C}$ range. The difference observed in these data arises in part from the difference in sensitivity between these techniques and in part from criterion taken for the determination of either the onset temperature or $T_{\min }$. This latter temperature is more precisely determined in the cooling curves from CCT, and as a consequence, it is frequently taken as the reference value, as was done by $\mathrm{Xu}$ et al. [31]. They observed a greater range of $T_{\min }$ values for $\mathrm{Ni}$ solidification, from $1142{ }^{\circ} \mathrm{C}$ to $915{ }^{\circ} \mathrm{C}$. Xu et al. [31] used a glass fluxing technique where the Ni-15.6 at. \% B alloy was remelted several times until the desired undercooling was observed. This procedure was intended to affect the heterogeneous nucleation of both nickel and nickel borides. However, the glass fluxing technique seems to mainly affect nickel nucleation, because for the constituents with nickel borides, the trends in undercooling and the solidification sequence reported by $\mathrm{Xu}$ et al. [23] are similar to those observed in this study.

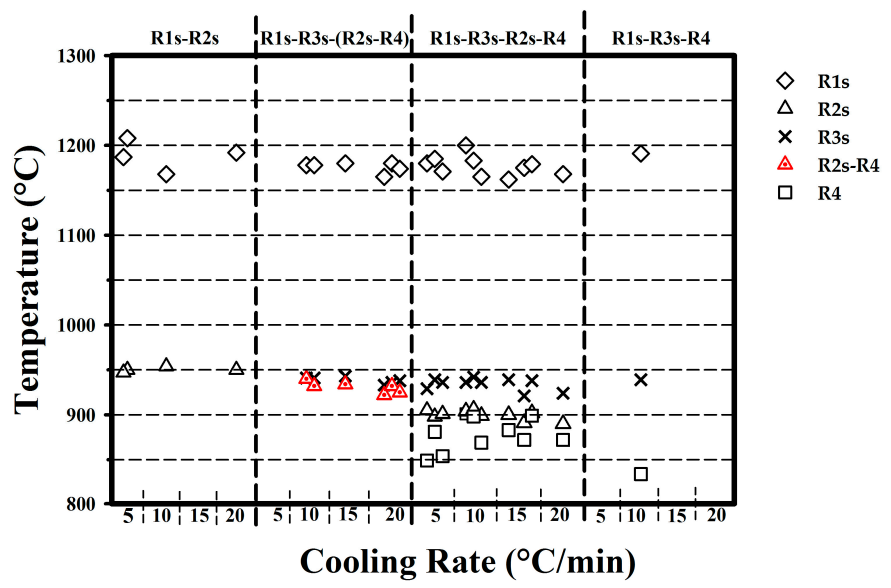

Figure 11. Onset temperatures of either peaks or sub-disturbances found in the thermal curves during cooling of the Ni-10.95 at. \% B-3.23 at. \% Si alloy in the DSC experiments.

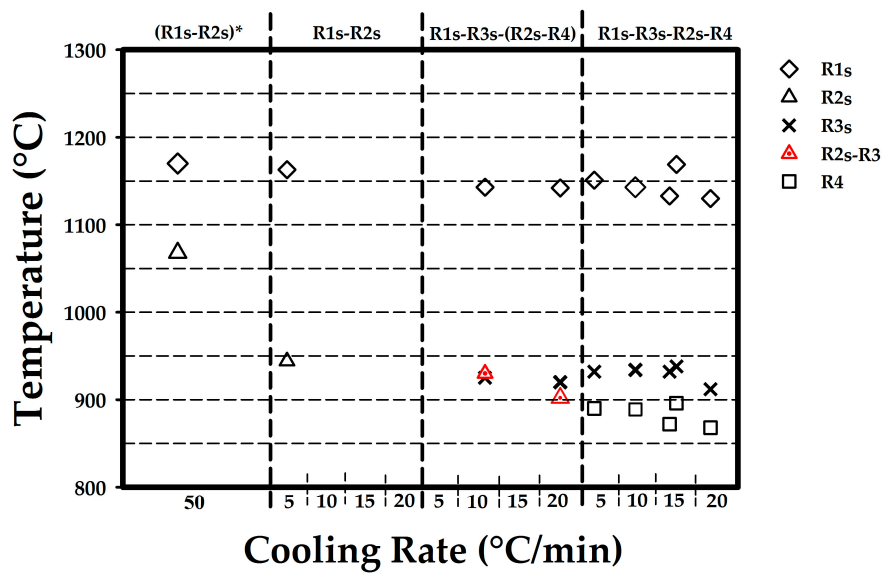

Figure 12. Minimal temperatures associated with the reaction plateau observed in the thermal curves from CCT, corresponding to samples of the Ni-10.95 at. \% B-3.23 at. \% Si alloy. $\left(R 1_{s}-R 2_{s}\right)^{*}$ data from the thermal cups. The data classified in the $\mathrm{R} 1_{\mathrm{s}}-\mathrm{R} 3_{\mathrm{s}}-\mathrm{R} 2_{\mathrm{s}}-\mathrm{R} 4$ sequence corresponds to CCT samples that have similar microstructural features than DSC samples showing this sequence, although $R 2_{s}$ is undetectable in CCT curves. 
In Figures 11 and 12 , it is observed that the $R 1_{s}-R 2_{s}$ reaction sequence occurs when the solidification temperature of the eutectic point is higher than $944^{\circ} \mathrm{C}$, which is equivalent to an undercooling below $156^{\circ} \mathrm{C}$, with respect to the $1100{ }^{\circ} \mathrm{C}$ eutectic temperature. This high undercooling is associated with a high recalescence, approximately $60^{\circ} \mathrm{C}$ in the CCT thermal curves. $\mathrm{Xu}$ et al. [23] found an undercooling of approximately $140{ }^{\circ} \mathrm{C}$ for this solidification sequence in the Ni-15.6 at. \% B alloy and a recalescence value of $56^{\circ} \mathrm{C}$. In the same figures, it is noted that $\mathrm{R} 3_{\mathrm{s}}$ appears at temperatures below $943{ }^{\circ} \mathrm{C}$ or undercoolings above $53{ }^{\circ} \mathrm{C}$, if the peak temperature of $\mathrm{R} 3_{\mathrm{m}}, 985^{\circ} \mathrm{C}$, is taken as a reference. The relatively low variation in the onset temperature of $\mathrm{R} 3_{\mathrm{s}}$ compared to that of $\mathrm{R} 2_{\mathrm{s}}$ suggests that the nucleation of the metastable constituent is less affected by remelting than the nucleation of the stable eutectic structure.

Regarding microstructural aspects, when the $R 1_{s}-R 3_{s}-\left(R 2_{s}-R 4\right)$ reaction sequence occurs, the quantity of the anomalous eutectic structure is larger than that observed in samples with the $R 1_{s}-R 3_{s}-R 2_{s}-R 4$ sequence. In the latter case, only a minor quantity of $\mathrm{Ni}_{3} \mathrm{~B}$ is observed in the interdendritic spaces. Comparison of Figures $9 \mathrm{c}, \mathrm{d}$ and $10 \mathrm{c}, \mathrm{d}$ leads to the observation of differences in the $\mathrm{Ni}_{3} \mathrm{~B}$ fraction formed during solidification. It is also observed that more dots are embedded in the $\mathrm{Ni}_{3} \mathrm{~B}$ phase of the resulting microstructure that underwent the $\mathrm{R} 1_{\mathrm{s}}-\mathrm{R} 3_{\mathrm{s}}-\left(\mathrm{R} 2_{\mathrm{s}}-\mathrm{R} 4\right)$ reaction sequence than those observed in the microstructure associated with the $R 1_{s}-R 3_{s}-R 2_{s}-R 4$ reaction sequence. This feature is more clearly observed in the micrographs in Figure 13.

The samples corresponding to the $R 1_{s}-R 3_{s}-\left(R 2_{s}-R 4\right)$ reaction sequence also provide some insight into the development of $R 3_{s}$, which was considered to be a eutectic reaction by $\mathrm{Xu}$ et al. [23]. In this regard, the microstructure shown in Figure 13a shows some interesting aspects. The microstructural constituent, initially metastable, shows a fibrous zone surrounded by a coarse zone with embedded dots. Assuming that the dots are formed during R4, the coarse zone must be related to a blocky $\mathrm{Ni}_{x} \mathrm{~B}_{y}$ metastable phase, which means that at least in part the formation of metastable constituent does not occur as a eutectic reaction. Thermodynamics calculations support this thought, if $\mathrm{Ni}_{23} \mathrm{~B}_{6}$ is considered to be the metastable phase. Figure 14 shows the solvus and liquidus lines corresponding to liquid-nickel equilibrium and those obtained by the Scheil-Gulliver model. Both simulations were performed by rejecting all solid phases except the Ni phase. It could be expected that the real composition of the liquid or solid phase must be located between the lines obtained from the simulations. In the same figure, a point corresponding to the $\mathrm{Ni}_{23} \mathrm{~B}_{6}$ phase is plotted at $985^{\circ} \mathrm{C}$. This figure shows that the calculations predict that the liquid phase at temperatures as low as $985^{\circ} \mathrm{C}$ has a $\mathrm{Ni}_{23} \mathrm{~B}_{6}$ composition; thus, this phase could be formed independently of the eutectic reaction.

The fibrous constituents could be of either eutectic or eutectoid nature. The fibrous constituents are finer in samples that underwent the $R 1_{s}-R 3_{s}-R 4$ reaction sequence than in samples that underwent the $R 1_{s}-R 3_{s}-\left(R 2_{s}-R 4\right)$ or the $R 1_{s}-R 3_{s}-R 2_{s}-R 4$ reaction sequence, as seen in Figure 13 . It is known that the fineness of the microstructural constituents increases as the reaction undercooling increases or its onset temperature decreases. In this regard, it is worth remembering that the onset temperature of $\mathrm{R} 3 \mathrm{~s}$ shows a lower variation than that of R4; see Figures 11 and 12 . This finding suggests a eutectoid nature of the fibrous constituents because they may have been formed over a large range of onset temperatures, which in turn may lead to the observed variation in fibrous fineness. However, more experimental evidence is needed in order to make a conclusion. 

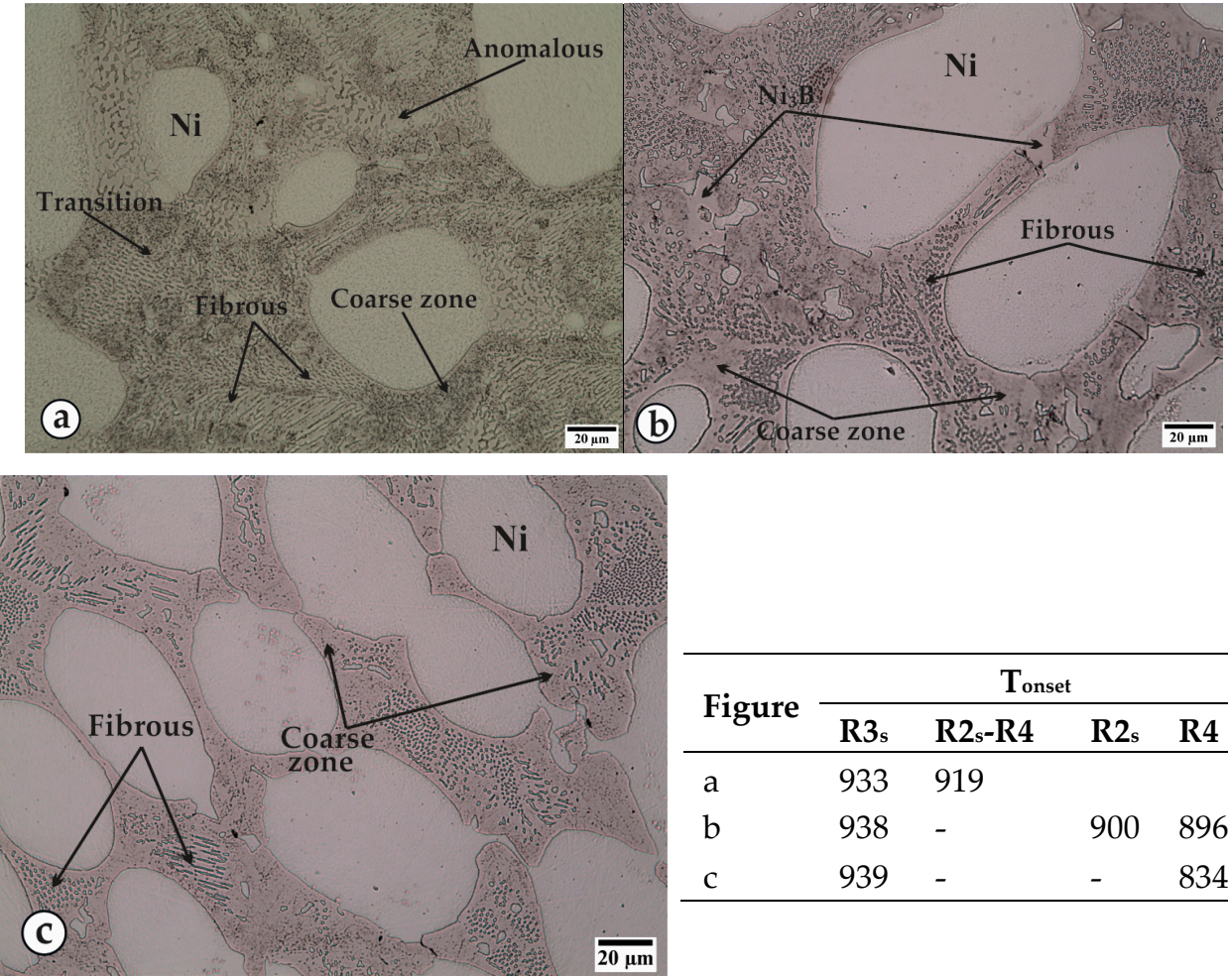

\begin{tabular}{|c|c|c|c|c|}
\hline \multirow{2}{*}{ Figure } & \multicolumn{4}{|c|}{ Tonset } \\
\hline & R3s & $\mathrm{R} 2 \mathrm{~s}-\mathrm{R} 4$ & $\mathrm{R} 2 \mathrm{~s}$ & R4 \\
\hline a & 933 & 919 & & \\
\hline b & 938 & - & 900 & 896 \\
\hline c & 939 & - & - & 834 \\
\hline
\end{tabular}

Figure 13. Micrographics of the microstructure of Ni-10.95 at. \% B-3.23 at. \% Si samples that show different solidification sequences during cooling from DSC at a rate of $10{ }^{\circ} \mathrm{C} / \mathrm{min}$ : (a) $\mathrm{R} 1_{\mathrm{s}}-\mathrm{R} 3_{\mathrm{s}}-\left(\mathrm{R} 2_{\mathrm{s}}-\mathrm{R} 4\right)$, (b) $\mathrm{R} 1_{\mathrm{s}}-\mathrm{R} 3_{\mathrm{s}}-\mathrm{R} 2_{\mathrm{s}}-\mathrm{R} 4$, and (c) $\mathrm{R} 1_{\mathrm{s}}-\mathrm{R} 3_{\mathrm{s}}-\mathrm{R} 4$.

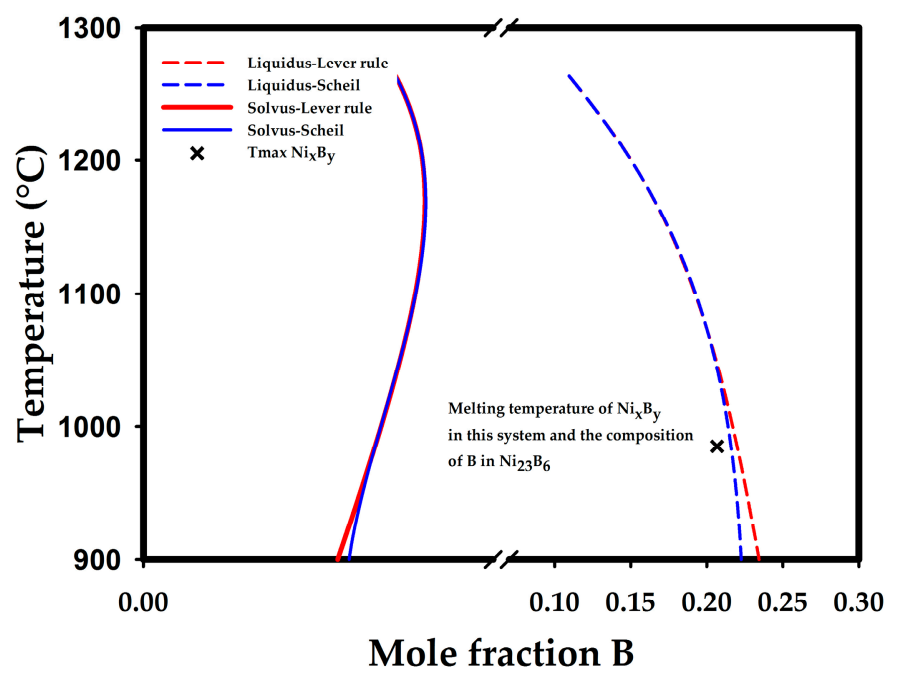

Figure 14. Liquidus and solvus lines calculated according the lever rule or the Scheil-Gulliver model. The calculations were made by rejecting all solid phases except the Ni phase.

In Figure 13a, some microstructural transitions from coarse metastable constituents to stable eutectic constituents are observed, which suggests the nucleation of the latter from the former. However, data from the thermal curves do not support this idea, see Figure 11, because after $R 3_{s}, R 2_{s}$ appears at a very different temperature with the corresponding undercooling variation. This relatively high variation in undercooling could oppose the idea of nucleation of the stable phase over the metastable phase. It is known that heterogeneous nucleation occurs when a suitable undercooling is reached, 
which must be maintained around a specific value if the crystal phase of the nucleation substrate is the same, which would be the case if the metastable phase acts as the substrate. Then, instead of nucleation of the stable constituent over the metastable constituent, a more complex mechanism would be involved in the transition between both constituents. This aspect needs further investigation in order to elucidate such mechanism.

Measurements of Vickers hardness were performed according to ASTM E384 standard [32] in a Wilson Hardness, model TUKON 2500. Average values from 15 measures performed in CCT samples are; 113,572 , and $646 \mathrm{HV} 0.3$, for $\mathrm{Ni}(\mathrm{fcc}), \mathrm{Ni}_{3} \mathrm{~B}$ of anomalous eutectic and fibrous constituent, respectively. Difference in HV0.3 among the two later constituents suggest a way to improve hardness of studied alloys. However, the stability of fibrous constituent at operational temperatures of glass mold, and wear behavior of microstructure with such constituent are subjects to be investigated.

\section{Conclusions}

The remelting of the Ni-10.95 at. \% B-3.23 at. \% Si alloy under Ar atmosphere favors the formation of different microstructural morphologies, which in turn are associated with different solidification sequences, as revealed by thermal analysis. The microstructural variation is the preferential formation of the anomalous eutectic structure instead of the lamellar structure, when the eutectic structure forms below $1073{ }^{\circ} \mathrm{C}$ and above of $944^{\circ} \mathrm{C}$. Further microstructural changes are associated with the nucleation and growth of a metastable constituent that appears when the onset of a second reaction observed during cooling in the thermal curves occurs below $944{ }^{\circ} \mathrm{C}$. While it was not possible to elucidate if this metastable constituent partially solidified in the eutectic structure, it was found that part of its solidification occurs by the formation of a coarse metastable $\mathrm{Ni}_{x} \mathrm{~B}_{y}$ phase. Simulations support this idea, if $\mathrm{Ni}_{23} \mathrm{~B}_{6}$ is considered to be the metastable phase. Regardless of the mechanism of $\mathrm{Ni}_{x} \mathrm{~B}_{y}$

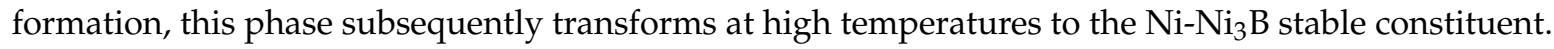

Acknowledgments: The author K. L. Fraga-Chávez acknowledges the scholarship provided by the National Council of Science and Technology (CONACyT) for the realization of this work.

Author Contributions: K. L. Fraga-Chávez performed the experiments; K. L. Fraga-Chávez and M. J. Castro-Román analyzed the data and wrote the manuscript together; L. E. Ramírez-Vidaurri, I. Aguilera-Luna and M. Herrera-Trejo critically revised the manuscript and participated in analyzing the data.

Conflicts of Interest: The authors declare no conflict of interest.

\section{References}

1. Lebaili, S.; Durand-Charre, M.; Hamar-Thibault, S. The metallurgical structure of as-solidified Ni-Cr-B-Si-C hardfacing alloys. J. Mater. Sci. 1988, 23, 3603-3611. [CrossRef]

2. Knotek, O. On the structure of Ni-Cr-B-Si hardfacing alloys and their bonding reactions. J. Vac. Sci. Technol. 1974, 11, 798-801. [CrossRef]

3. Ajao, J.; Hamar-Thibault, S. Structure observations by high-resolution electron microscopy of Ni-B melt-spun alloys. J. Mater. Sci. 1989, 24, 3647-3659. [CrossRef]

4. Ajao, J.; Hamar-Thibault, S. Influence of additions on the solidification behaviour of Ni-B alloys-Crystallography of Ni-Ni3B eutectic. J. Mater. Sci. 1988, 23, 1112-1125. [CrossRef]

5. Morris, D.G. Glass formation and crystallisation in Ni-Si-B alloys-II. Crystal formation on annealing. Acta Metall. 1984, 32, 837-849. [CrossRef]

6. Morris, D.G. Crystallization embrittlement of Ni-Si-B alloys. J. Mater. Sci. 1985, 20, 331-340. [CrossRef]

7. Zhu, C.L.; Wang, Q.; Wang, Y.M.; Qiang, J.B.; Dong, C. Ni-based B-Fe-Ni-Si-Ta bulk metallic glasses designed using cluster line, minor alloying, and element substitutions. Intermetallics 2010, 18, 791-795. [CrossRef]

8. Ohodnicki, P.R.; Cates, N.C.; Laughlin, D.E.; McHenry, M.E.; Widom, M. Ab initio theoretical study of magnetization and phase stability of the (Fe,Co,Ni)23B6 and (Fe,Co,Ni)23Zr6 structures of $\mathrm{Cr} 23 \mathrm{C} 6$ and Mn23Th6 prototypes. Phys. Rev. B Condens. Matter Mater. Phys. 2008, 78, 1-13. [CrossRef]

9. Knotek, O.; Lugscheider, E. Brazing Filler Metals Based on Reacting Ni-Cr-B-Si Alloys. Weld. Res. Suppl. 1976, 55, 314-318. 
10. Jalilian, F.; Jahazi, M.; Drew, R.A.L. Microstructural evolution during transient liquid phase bonding of Inconel 617 using Ni-Si-B filler metal. Mater. Sci. Eng. A 2006, 423, 269-281. [CrossRef]

11. Yuan, X.; Kang, C.Y.; Kim, M.B. Microstructure and XRD analysis of brazing joint for duplex stainless steel using a Ni-Si-B filler metal. Mater. Charact. 2009, 60, 923-931. [CrossRef]

12. Tanaka, K.; Hidaka, K. Hard Facing Nickel-Base Alloy. U.S. Patent 4,404,049, 13 September 1983.

13. Gurumoorthy, K.; Kamaraj, M.; Rao, K.P.; Rao, A.S.; Venugopal, S. Microstructural aspects of plasma transferred arc surfaced Ni-based hardfacing alloy. Mater. Sci. Eng. A 2007, 456, 11-19. [CrossRef]

14. Ming, Q.; Lim, L.C.; Chen, Z.D. Laser cladding of nickel-based hardfacing alloys. Surf. Coat. Technol. 1998, 106, 174-182. [CrossRef]

15. Hampton, M.D.; Schur, D.V.; Zaginaichenko, S.Y.; Trefilov, V.I. Hydrogen Materials Science and Chemistry of Metal Hydrides; Springer: Berlin/Heidelberg, Germany, 2012.

16. Davis, J.R. Handbook of Thermal Spray Technology; ASM International: Novelty, OH, USA, 2004.

17. Teramoto, T.; Hidaka, K. Hard Facing Nickel Base Alloy. U.S. Patent 4,425,300, 10 January 1984.

18. Davis, J.R. Nickel, Cobalt, and Their Alloys. Asm Specialty Handbook; ASM International: Novelty, OH, USA, 2000.

19. Lebaili, S.; Hamar-Thibault, S. Equilibres Liquide-Solide Dans Le Système Ni-B-Si Dans la Region Riche en Nickel. Acta Metall. 1987, 35, 701-710. [CrossRef]

20. Flemings, M.C. Solidification Processing; Wiley Online Library: Hoboken, NJ, USA, 1974.

21. Kurz, W.; Fisher, D.J. Fundamentals of Solidification; CRC Press: Boca Raton, FL, USA, 1998.

22. Baricco, M.; Ferrari, E.; Battezzati, L. Undercooling experiments in a high temperature differential scanning calorimeter. In Materials Research Society Symposium_Proceedings; Materials Research Society: Pittsburgh, PA, USA, 1996; Volume 398, pp. 81-86.

23. Xu, J.; Liu, F.; Dang, B. Phase selection in undercooled Ni-3.3 Wt Pct B alloy melt. Metall. Mater. Trans. Phys. Metall. Mater. Sci. 2013, 44, 1401-1408. [CrossRef]

24. Xu, J.F.; Liu, F.; Xu, X.L.; Dang, B. Undercooled solidification of Ni-3.3 wt-\%B alloy and cooling curve description. Mater. Sci. Technol. UK 2013, 29, 36-42. [CrossRef]

25. Xu, J.; Liu, F.; Zhang, D. Phase selection of undercooled solidification of Ni-4.5 wt\% B alloy. J. Mater. Res. 2013, 28, 3347-3354. [CrossRef]

26. Ajao, J.A. Preparation and Structural Characterization of Vanadium Doped Ni-B Binary Hard Alloys. J. Miner. Mater. Charact. Eng. 2010, 9, 559-568. [CrossRef]

27. Boettinger, W.J.; Kattner, U.R.; Moon, K.W.; Perepezko, J.H. DTA and Heat-Flux DSC Measurements of Alloy Melting and Freezing; Citeseer: State College, PA, USA, 2006.

28. Croker, M.N.; Baragar, D.; Smith, R.W. Anomalous eutectic growth. II. The relationship between faceted/non-faceted eutectic structures. J. Cryst. Growth 1975, 30, 198-212. [CrossRef]

29. Clopet, C.R.; Cochrane, R.F.; Mullis, A.M. The origin of anomalous eutectic structures in undercooled Ag-Cu alloy. Acta Mater. 2013, 61, 6894-6902. [CrossRef]

30. Wei, X.X.; Lin, X.; Xu, W.; Huang, Q.S.; Ferry, M.; Li, J.F.; Zhou, Y.H. Remelting-induced anomalous eutectic formation during solidification of deeply undercooled eutectic alloy melts. Acta Mater. 2015, 95, 44-56. [CrossRef]

31. Xu, J.; Liu, F.; Zhang, D. In situ observation of solidification of undercooled hypoeutectic Ni-Ni ${ }_{3} \mathrm{~B}$ alloy melt. J. Mater. Res. 2013, 28, 1891-1902. [CrossRef]

32. ASTM E384: Standard Test Method for Knoop and Vickers Hardness of Materials. In ASTM Standards; ASM International: Novelty, OH, USA, 2012; pp. 1-43.

(C) 2017 by the authors. Licensee MDPI, Basel, Switzerland. This article is an open access article distributed under the terms and conditions of the Creative Commons Attribution (CC BY) license (http://creativecommons.org/licenses/by/4.0/). 